\title{
Implementing Six Sigma Techniques in Accounting Information Quality Management for China's Securities Companies
}

\author{
LI Li \\ School of Business \\ Beijing Language and Culture University \\ Beijing, China
}

\begin{abstract}
In recent years, China's securities companies have experienced a wave of financial innovation in their business practices, especially in the capital intermediary business (CIB). Thus, innovative products and business lines pose significant challenges to the traditional way of information processing, which has a direct effect on the quality of accounting information. The need for an effective maintenance of information quality to meet the various demands from both internal and external parties requires some constructive researches related to the accounting information quality (AIQ) control. This paper presents the application of the six-sigma DMAIC methodology to the accounting information production of China's securities companies. The results suggest that reforms at current stage should be focused on business culture, institutional reconstruction as well as training and educational system.
\end{abstract}

Keywords-Six Sigma; accounting information quality management; DMAIC; securities companies; capital intermediary business

\section{INTRODUCTION}

With the development of China's capital market, Chinese securities companies have evolved for nearly three decades and now offer a variety of financial products and services including but not limited to securities underwriting, brokerage, proprietary trading and asset management. However, these firms are still far from catching up fully-fledged western financial institutions, and their activities tend to be more focused in particular areas. Moreover, accounting system of Chinese securities firms is less integrated with the transaction processing, and the accounting information quality (AIQ) depends mostly on the operational effectiveness and efficiency of financial reporting department.

Since 2012, sustained innovation in the financial sector has put China's securities companies on a fast track, and lead to the consequent development of a series of financial derivative instruments, such as stock index futures, treasury bond futures, stock options, the New Third Board. From 2012 to the June 2015, several listing securities companies made their Initial Public Offerings (IPOs) and significantly expanded their size of capital. Meanwhile, various kinds of capital intermediary business (CIB) products, for instance, margin financing and securities lending business, securities backed lending, return swap, market-making, and quantitative trading, which are supported by adequate capital, have gained a good chance for further development. Recently, the proportion of CIB to the assets, liabilities and income has continuously improved in some China's biggest securities companies. Reviewing the development of the US securities industry, it is easy for us to find out that in the very beginning of the 1980s, American investment banks succeeded in transforming themselves from channel service providers to capital intermediaries by financial innovation in products design, sales, and service mode. As statistics show, the net income of the US securities sector had expanded 54 times from 4 billion dollars to 221.1 billion dollars during the four decades since 1967. An in-depth examination would reveal that channel service income including brokerage and commission income had increased by 25 times, other related income had increased by 127 times and the proportion of channel service income to net income had decreased from 71 percent to 33 percent [6]. It's clear that contemporary business model of China's securities companies today, which features a high proportion of channel service, closely resembles its US counterpart of the 1960s and 1970s.

Under the background of financial innovation, rapid growth in business activity is taking place in an ever-changing sector and large amounts of trading and derivative financial instruments have been supplied to the capital market. This new trend results in challenges for AIQ control in the aspects of accuracy, timeliness and integrity. According to Li [5], in many China's securities companies, the major challenges are as follows: i) the collection of transaction information of trading department is decentralized; ii) some trading and derivative financial instruments are being confronted with the problem of multi-clearing system, and challenged by the scalability of their present clearing system; iii) during the course of collection, part of new trading and derivative financial instruments especially those which are recorded by manual operation or fail to be supported by external system are susceptible to errors and omissions. Properly balancing the conflict between newly developed services and the poor quality control of accounting information has become one of urgent problems faced by China's securities companies. 


\section{Specialties of AIQ MANAgement of Securities COMPANIES}

In essence, accounting information quality management is the service quality control, which is characterized by some typical features of service industry: latency, volatility, and vagueness [1]. In addition, securities sector is capital concentrated and human-incentive, IT oriented and highly risky. Thus, the industry determines that its accounting information producing process has two outstanding characteristics. First, the effect of artificial factors on the quality of accounting information has been strengthened. In the case of frequent innovation of products, the production of accounting information fails to achieve a stable status. Human factors, such as reassignment of staff responsibilities, sector restructuring, simplification and recycling of procedures, are variable and could be more likely than not to impose negative impacts on AIQ control. In different steps of accounting information production, disagreements on policy application could arise between various departments due to inconsistent understanding on a certain product, thus totally affect the overall quality of accounting information.

Second, the problem of cross-sectoral and cross-accounting-books coordination has become increasingly important. At present, both domestic and international large securities companies, especially those operated in groups, adopt an integrated management system. Under such management style, the production of accounting information would be challenged by the cross-time zones, cross-regions, cross-sectors and cross-accounting-books nature of their operation. In every trading day, the collection and consolidation of accounting information is a huge task with complicated process. Due to locality, staffs from various departments are susceptible to neglecting or sometimes even misunderstanding the real need of other departments. And it is common that communication among sectors is poor. In some of China's securities companies, management layer even has no idea about a systemic management of ordinary operation. Due to the lack of cross-sectoral mechanism for an effective coordination, it is popular that different departments act according to their each own free will [2].

It is a fact that methodologies and techniques employed by China's securities companies in AIQ control are generally lagged behind by international best practice. In order to improve the quality of accounting information and meet the needs of various users for accounting statements, it is necessary for these companies to draw upon international leading practices, and utilize advanced concepts and modes in their operations and management. Since the end of 1980s, Six Sigma management has evolved into an advanced mode implemented by many famous Multinational Companies (MNCS) in the field of quality management. The paper is designed to discuss the necessity and feasibility of improving China's securities companies' AIQ control by using Six Sigma techniques.

\section{Six Sigma IN AIQ Management OF SECURITIES COMPANIES}

In 1987, Motorola Corp. used Six Sigma Management in its quality improvement as a whole, and started a quality revolution based on modern statistical applications.

\section{A. Six Sigma Management}

Used in statistical quality control, sigma is a measure of process capability to meet quality requirement. In other words, with a higher sigma level, the ability of processes to satisfy the quality control will also be higher. The Six Sigma Management is defined as a set of techniques and tools for process improvement that make the Eigen value of process quality be at least six sigmas. Six Sigma seeks to improve the quality of the output of a process by identifying and removing the causes of defects and minimizing variability in business processes. It uses a set of quality management methods, mainly empirical, statistical ones [10]. The Define-Measure-Analyze-Improve-Control (DMAIC) improvement cycle is the core tool used to drive six sigma projects.

Since birth, theories and methodologies of Six Sigma have been improved and utilized by developed economies. Starting mid-1990s, Six Sigma has been highly praised by top CEOs such as Jack Welch from General Electric, and was introduced to many famous manufacturing MNCS in electronic, mechanical, chemical, metallurgical industries, such as Ford, Caterpillar, Dow Chemical, DuPont, ABB and Samsung. All of these industry giants achieved a great performance in their business. In the 21 century, the scope of Six Sigma application has been expanded from manufacturing sector into service. An increasing number of global service giants such as Citibank, HSBC, and Amazon succeeded in strengthening the core competitiveness by using Six Sigma. In China, since 2002, some firms began to introduce Six Sigma, for example, Lenovo, Haier, Chunlan, Hainan Airlines [7]. As a whole, Six Sigma was carried out mainly by foreign firms or foreign joint venture firms, and firms from service part are few. It is noticeable that in financial service sector, in contrast with western countries, there are a few China's enterprises from banking, capital market actively engaged in implementing Six Sigma in their operation.

Attentively, in its application of service sector, Six Sigma method has been expanded from the initial quality control of products to optimization design and improvements of system of the overall business processes. As for the method innovation, Six Sigma has developed from traditionally statistical technique into a combination of advanced management theories and methods which focus on lean production, balanced scorecard, concurrent engineering.

\section{B. Significance for China's Securities Companies to Introduce Six Sigma in AIQ Management}

It is helpful for China's securities companies to establish new concepts and strategy for their financial information management system. Six Sigma depends heavily on data and fact, facilitates the unity of knowledge, promotes strategy management and creates quality-oriented culture of enterprises. 
In introducing Six Sigma, China's securities companies will have to reconstruct and optimize the main procedure of accounting information production. And such reform will not only probe the crux of accounting information problem, but also facilitate an efficient communication among financial department, trading department, IT department and other supportive departments. Moreover, the reform will stimulate the establishment of cross-sectoral coordinative mechanism and promote efficiency, which satisfy the information quality requirements of timeliness, relevance and faithful representation.

\section{DMAIC CyCle FOR AIQ CONTROL OF SECURITIES COMPANIES}

DMAIC cycle is the key tech of Six Sigma method. It refers to a data-driven improvement cycle used for improving, optimizing and stabilizing business process and designs. The name is an abbreviation of the five improvement steps the cycle comprises: Define, Measure, Analyze, Improve, and Control [9]. To solve the problem of errors and omissions existed in AIQ management for trading and derivative instruments, this part will apply the framework of DMAIC cycle to prioritize areas of improvement for AIQ control of China's securities companies.

\section{A. Define}

This step aims to clearly articulate the business problem, goal, potential resources, project scope and high-level project timeline. In this stage, securities companies need to form the project team and define the scope of problems of AIQ control brought out by trading and derivative financial instruments from the perspective of firm's strategy. Problems design of this stage usually follows the logical order of macro then micro. Presently, the following questions should be considered in the design: i) Whether there is a clear firm strategy to improve the AIQ management for trading and derivative financial instruments or not? ii) What are the problems of AIQ system due to the increase in trading and derivative instruments? iii) When did these problems happen for the first time? Whether these problems occur frequently? iv) Is there an existing index to measure the frequency of repeating and occurrences? If there is, what is it? v) How serious are those problems of AIQ control resulted from trading and derivative instruments? vi) How can problems of quality control be recognized and analyzed?

In order to exhibit the multi-function of project, many MNCS used Suppliers-Inputs-Process-Outputs-Customers (SIPOC) processing figure to define their process. It is emphasized that SIPOC figure summarizes the inputs and outputs of process improvements in a macro sense, focusing on the five points: Suppliers, Inputs, Process, Outputs and Customers. Fig. 1 shows the major process management and relative functions of AIQ control of securities companies for trading and derivative financial instruments [4].

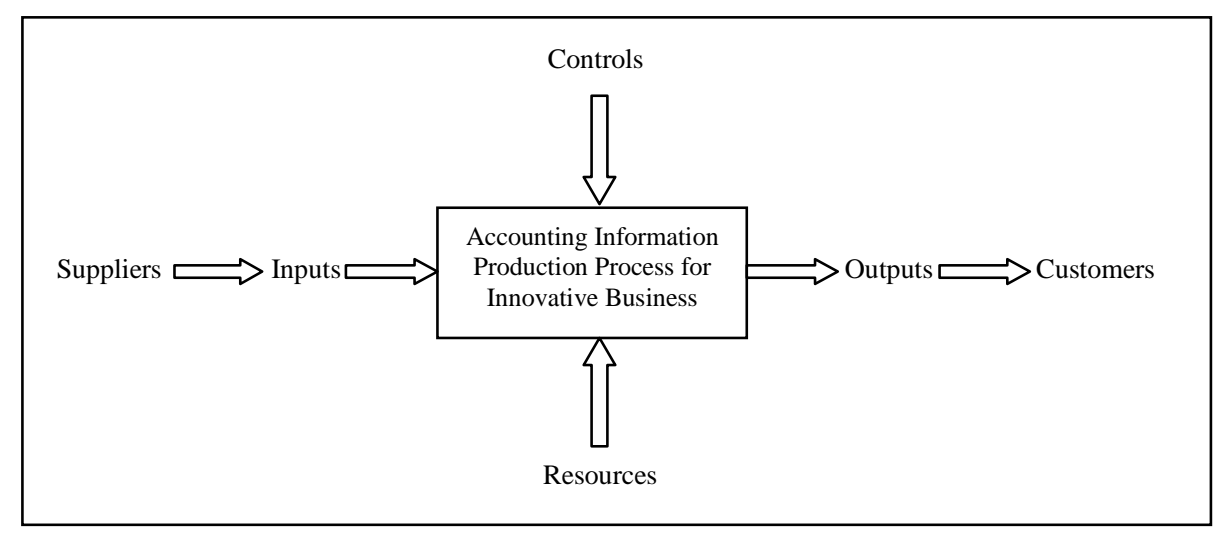

Fig. 1.SIPOC for AIQ Management of Securities Companies

The suppliers of accounting information cover the front, middle and backup departments, ranging from financial sector, clearing department, trading sector, among others. The customers of accounting information about trading and derivative financial instruments of securities companies include external parties such as investors, creditors, regulators and other institutions, and internal managers of all lines. Additionally, in defining the scope of project, it is necessary to identify the basic procedure of producing accounting information for trading and derivative financial instruments in order to recognize the cross-sectoral team of the project.
It is generally accepted that the accounting information producing of China's securities companies must meet the requirements of timeliness, reliability and faithful representation. It is a fact that some newly-developed products are susceptible to errors and omissions in the course of information collection. Thus, project team is advised to make cross-sectoral and cross-accounting-books investigation by staff discussion, questionnaire, spot check test for day-to-day account, field visits among other methods that help staff obtain common knowledge about the features of the products and market conditions, and furthermore understand the seriousness of problem and reasons for AIQ management of trading and 
derivative financial instruments. As causes for accounting information problems differ among different kinds of trading and derivative financial instruments, project term can design different criterion to classify new products according to trading size, return rate (includes floating rate of return), frequency of trading or market share. Such a method facilitates both defining the scope of process that needs to be improved and setting a reasonable project goal according to the actual situation of company as well as the average level of securities industry. In project planning, it is also necessary to define the importance of quality.

\section{B. Measure}

In theory, measuring is a data collection step to establish process performance metric baseline(s). The measure phase starts with process analysis to identify the gap between current and required performance. And it concentrates on data collection to create a process performance capability for project metric, and ends with assessing the measurement system. In this stage, securities companies need to measure the current performance of trading and derivative financial instruments and the status quo of accounting information producing process in light for the detailed flow diagram. Fig. 2 demonstrates the basic procedure of producing accounting information for trading and derivative financial instruments in China's securities companies [5]. It is clear that accounting information production of trading and derivative financial instruments involves many departs from front, middle, and backup lines. Formulating this figure presents a good opportunity for involved departments to enhance communication and reach agreement on the real procedures of accounting information production of newly supplied products.

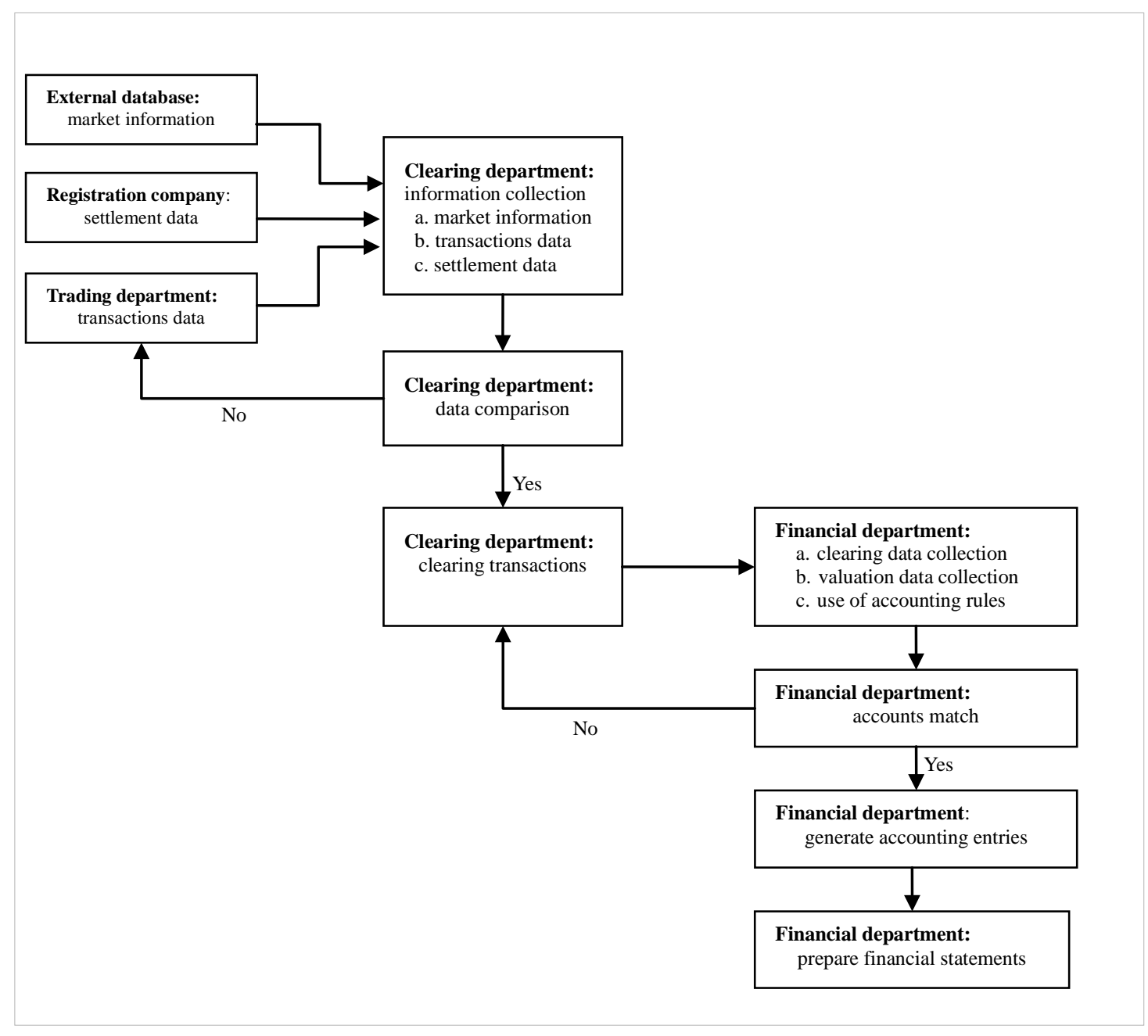

Fig. 2.Accounting Information Production Process for Innovative Business in Chinese Securities Companies

Upon finishing the figure of procedure, project team can use cause and effect diagram tech to find out the possible reasons aroused from factors such as staffs, business, internal rules, and external environment and so on [8]. In appearance, the role of cause and effect diagram lies in analyzing the problems, the underlying reasons as well as their relationship for AIQ management of new business lines. In fact, the cause and effect diagram and its formulation process require active participation of all departments in the company. Such activity will simulate an overall diagnostic feature of internal management knowledge. Furthermore, it is an active attempt for managers to reach a grand unified concept about efficient 
management. On the basis of cause and effect analysis, the project team can look for the breakthrough point for optimizing process of AIQ management by simplifying steps, integrating human resources, adjusting position, innovating examining approaches and etc..

In making a comprehensive measurement on current process performance capability, the team can identify key factors which influence the working efficiency of accounting information system for trading and derivative financial instruments by analyzing quantificational data such as on-line delay rate and quality rate etc.. In practice, it is suggested that according to category of new products, the project team should compare a particular product before and after adjusting it. Quantificational analysis enables the project team to make an induction about non-performance ratio of accounting information, distribution of default ratio of different categories of products. Combined with stabilization analysis, the team will check and confirm the steps in problem, and identify the major causes influencing AIQ of trading and derivative financial instruments.

\section{Analysis}

The main goal of analyzing phase is to identify, validate and select root cause for elimination. After listing all potential causes of the accounting information problem, the team should select the significant root causes via cause analysis. In this stage, cyclical analysis approach is widely used, and at the same time, statistical conjecture, some statistical techniques such as hypothetical test and regression analysis will be used to determine and verify the root reasons for accounting information problems. Then, in order to find out the effects brought out by those root factors on accounting information system efficiency, the team should analyze data and understand the magnitude of contribution of each root cause. It is suggested that a detailed process map should be created to help pin-point where in the process the root causes reside, and what might be contribution to the occurrence of accounting information problems. Based on the analyzing findings, the optimal path will be planned.

\section{Improve}

Upon finishing the previous three steps, the project team will identify a basket of solutions to the problem of AIQ. The basket of solutions can be designed in part or in whole. In this step, the following solutions should be in place as soon as possible: i) to establish a devoted team to solve the cross-sectoral communication problem; ii) to avoid repeated confirmation and improve communication efficiency of accounting information for trading and derivative financial instruments, introduce an efficient classification review mechanism; iii) to solve the quality problem resulting from operational errors of the staff, set reminders and improve record of personal bad rate, meanwhile strengthening the accountability system by stipulating that anyone whose accumulated rate reach the threshold be added to the blacklist, or even removed from current position. It is important to note that coming up with solutions is not the end of improvement. The project team also needs to evaluate the advantages and disadvantages of each solution in feasibility, input costs and cycle. And generally, the simpler and easier solutions would be better. As He Zhen claimed, sometimes project team would implement solutions which are not the best in technology, but those which are the most widely accepted in the company [4].

\section{E. Control}

In this final step of DMAIC, the project team focuses on sustaining the gains. To ensure sustainable achievements, it is needed for the team to assess the stability of the improvements regularly. According to the assessment findings, the team monitors the improvements by making a control plan, updating document, business process and training records. The controlling phase not only reaches sustainable success, but embodies those improvements in the management system of securities companies and establishes a dynamic process control system.

\section{Suggestions FOR ChinA’s SECURITIES COMPANIES IN INTRODUCING SIX SIGMA}

In the background of policy adjustment and development of multi-layered capital market, China's securities companies have increased their asset size, business lines, as well as operating income. Meanwhile, securities companies are embracing a younger generation of financial talents with global business mindset. Such changes provide a solid foundation for the introduction of Six Sigma into China's securities companies. In current period, several aspects of measures should be taken to cope with this need as follows.

\section{A. Establish Firm Culture Oriented by Six Sigma Philosophy}

Widely accepted Six Sigma philosophy is the ideological foundation for a sound introduction of Six Sigma techniques into China's securities companies for improving quality management of accounting information. Empirical evidence shows that the most effective mode for the successful implementation of Six Sigma techniques is from top to bottom. Ideal transformation and leading role played by leaders will have a strong influence on the implementation effects of Six Sigma [1]. In order to combine the Six Sigma culture with firms' culture effectively, many firms choose the high-level training as the breakthrough and strengthen the promotion of Six Sigma philosophy, and try to penetrate it into firms' strategy and development planning. All levels of managers from China's securities companies especially the core management should play an active role as advocates and supporters. Six Sigma culture is more likely to be integrated into corporate values and strategy development only if all the super leaders accept the philosophy and promote it actively. The end result is a new corporate culture system which will be oriented by Six Sigma management.

\section{B. Improve Efficient Training and Educational System}

Human are the most critical and direct factor in promoting accounting information production process for trading and derivative financial instruments of China's securities companies. Securities companies, who intent to introduce Six Sigma techniques into AIQ management successfully, should erect an efficient training and educational system for their employees. Currently, China's securities companies can take awareness training programs systematically to create a healthy atmosphere of corporate culture by establishing specialized agencies or employing service outsource. As to the 
main content for training programs, the knowledge about pricing, assessing principle for newly developed trading products should be included. Training programs should also cover industry rules and accounting system in order to unite the nature of products and combine accounting requirements for data collection with demand of customers [3]. In addition, training for staffs in the field of data analysis should be emphasized, especially the analysis method of accounting information producing process for innovative products and statistical tools.

\section{Reform Organization System}

The introduction of Six Sigma for the AIQ management is a big challenge for China's securities companies. It is necessary to establish a project team taking responsibility to execute Six Sigma techniques, and in accordance with the importance to the project, the team can be divided into the core team and the service team. The core team not only takes charge of project selection based on strategy goal of firm, makes a detailed time schedule for execution, and makes cross-sectoral coordination of resources; but also takes in charge of assessment and regulation of project. On the other hand, the service team will be responsible for the organization of project training and teaching, providing information consultation. Furthermore, securities companies should establish a special team to solve the problem of discrepancy in rules among different sectors and statements. In practice, this special team takes responsibility of coordinating accounting and clearing rules of different sectors, guarantee a sound flow of cross-sectoral information and communication, integrate internal transactional system and clearing system of firm.

\section{REFERENCES}

[1] Gun Yunmiao, Zhu Jinfu, "Six Sigma Management in Service Industry ”, Journal of Commercial Research, 2005(23), pp.25-28. (in Chinese)

[2] Guan Liming, "Problems and Suggestions of Financial Management for China's Securities Companies ,’Journal of Money China, 2010(3), pp.5-6. (in Chinese)

[3] Guo Wanli, "Thought of Locate and Transformation of Financial Staff in the Big Data Era,” Journal of Finance and Accounting, 2015(10), pp.10-12 . (in Chinese)

[4] He Zhen, "Six Sigma Management," By China Renmin University Press, 2014.(in Chinese)

[5] $\mathrm{Li} \mathrm{Li}$, "Research on Quality Control for Accounting Information for Securities Trading Business,” Journal of Friends of Accounting, 2016(5), pp.93-96. (in Chinese)

[6] Wang Dongming, "Business Model Upgrade for Securities Industry,” China Finance 40 Forum, 2011(4). http://www.cf40.org.cn/plus/view.php?aid=3859. (in Chinese)

[7] Wu Limin, "Discussion on the Essence of Six Sigma Management," Journal of Wuhan Polytechnic University, 2004(4), pp.70-73. (in Chinese)

[8] Zhang Dong, Yu Feng, Min Yaneng, “Casebook of Lean Six Sigma”, By Donghua University Press, 2012. (in Chinese)

[9] https://en.wikipedia.org/wiki/DMAIC

[10] https://en.wikipedia.org/wiki/Six_Sigma 